\title{
DIFFUSE IDIOPATHIC SKELETAL HYPEROSTOSIS (DISH) OF THE SHOULDER: A CAUSE OF SHOULDER PAIN?
}

\author{
By CH. BEYELER*, P. SCHLAPBACH*, N. J. GERBER*, J. STURZENEGGER*, \\ H. FAHRER*, SJ. VAN DER LINDEN* ${ }^{*}$ U. BÜRGI $\dagger$, W. A. FUCHS $\ddagger$ AND \\ H. EHRENGRUBER $§$ \\ Departments of ${ }^{*}$ Rheumatology, †Internal Medicine, $\ddagger$ Radiology and $§$ Data Processing, University of \\ Berne, Inselspital, CH-3010 Berne, Switzerland
}

\begin{abstract}
SUMMARY
Shoulder pain is a common complaint and shoulder hyperostosis a frequent radiological condition. However, little is known about the association between the clinical and radiological findings. To evaluate the clinical relevance of shoulder hyperostosis we performed a controlled, blind study of 99 hospitalized probands with and without thoracospinal hyperostosis on lateral chest $\mathrm{X}$-rays. The study included grading of the shoulder hyperostosis on the basis of three bilateral standard radiographs, assessing shoulder pain in a standardized way by an interviewer and recording extraskeletal causes of shoulder pain. The prevalence of shoulder hyperostosis was doubled in probands with thoracospinal hyperostosis compared to controls $\left(\chi^{2}=5.90, P<0.025, n=99\right)$. Shoulder hyperostosis, irrespective of thoracospinal hyperostosis, predisposed to shoulder pain $\left(40 \%\right.$ versus $\left.18 \%, \chi^{2}=4.06, P<0.05, n=74\right)$. Shoulder hyperostosis in combination with thoracospinal hyperostosis (shoulder DISH) predisposed to shoulder pain to an even greater extent $\left(46 \%\right.$ versus $12 \%, \chi^{2}$ $=6.64, P<0.01, n=47$ ). We conclude that shoulder hyperostosis is a radiological finding of potential clinical relevance.
\end{abstract}

KEY words: Shoulder, Hyperostosis, Forestier's disease, Ankylosing vertebral hyperostosis, Radiographs, Pain.

DIFfuse idiopathic skeletal hyperostosis (DISH) is common, and was known for several decades as senile ankylosing hyperostosis of the spine $[1,2]$, ankylosing hyperostosis of Forestier and Rotes-Querol, hyperostotic spondylosis or ankylosing vertebral hyperostosis. Due to the occurrence of both spinal and extraspinal findings, the term diffuse idiopathic skeletal hyperostosis (DISH) was introduced [3]. It is characterized by spinal anterolateral ligamentous calcification or ossification [3-6], and extraspinal enthesial ossification with bony spur formation [3-5], commonly seen at sites such as shoulder, elbow, knee and heel [7-17].

The radiological findings of idiopathic shoulder hyperostosis have been well described [8, 10, 12]. Criteria for radiological grading have not yet been published and the clinical relevance of the radiological findings is still a matter of dispute. Several studies have suggested that peripheral joint involvement may lead to symptoms, including pain of the shoulder $[3,4,7-9$, 13]. However, these studies have not included controls. We have performed the first such study with the following aims: (1) to develop radiological criteria for shoulder hyperostosis grading; (2) to evaluate a possible association between thoracospinal hyperostosis and shoulder hyperostosis; (3) to clarify the clinical relevance of shoulder hyperostosis as a cause of shoulder pain.

\section{MATERIAL AND METHODS}

Based on the screening of consecutive routine lateral chest X-rays done on admittance to two departments of

Submitted 16 October 1989; revised version accepted 13 March 1990.

Correspondence to Prof N. Gerber, Department of Rheumatology, University of Berne, Inselspital, CH-3010 Berne, Switzerland. internal medicine and one of cardiovascular surgery, 284 age- and sex-matched probands with and without thoracospinal hyperostosis were recruited. Deliberately, no oncological, rheumatological, orthopaedic or neurological probands were included. Of the above 284, 99 gave consent to a complete radiological examination of both shoulders and are the focus of this study.

Clinical symptoms such as shoulder pain during the last 6 months or before, history of work and the cause of admission to hospital were collected by two independent, blind interviewers (CHB, EH), using a standardized questionnaire. Classification of physical work to be considered as heavy or light was done according to a convention between the two interviewers. Extraskeletal causes of shoulder pain were recorded by a blind physician (UB) according to the medical reports.

Lateral chest X-rays were graded blind by a rheumatologist (PS) as follows [6]:

\section{Thoracospinal hyperostosis DISH grading}

\section{Grade 0: no ossification;}

Grade I: prevertebral and/or prediscal ossification at one or two vertebral bodies of the spine or one bridging ossification;

Grade II: flowing continuous prediscal and/or prevertebral ossification along three or more vertebral bodies or two bridging ossifications;

Grade III: three or more bridging prediscal or prevertebral ossifications.

The intervertebral discs of the hyperostotic segments did not show any degenerative, inflammatory or dysplastic abnormalities [6].

Probands with grades 0 or I were considered as 'thoracospinal hyperostosis absent' (controls), those with grades II or III as 'thoracospinal hyperostosis present'.

The following three shoulder $\mathrm{X}$-rays were per- 
formed (anteroposterior view direction): 20 degrees craniocaudal tilt with hanging upper arm in 45 degrees external and 45 degrees internal rotation, respectively; horizontal beam tilt with upper arm in 90 degrees abduction and maximal external rotation. All shoulder $\mathrm{X}$-rays were graded blindly and independently by a rheumatologist (NJG) and a radiologist (WAF) as follows:

Grade 0: none or only one attached ossification of less than $2 \mathrm{~mm}$;

Grade I: two or more ossifications of less than $2 \mathrm{~mm}$ or one ossification of $2-3 \mathrm{~mm}$;

Grade II: two or more ossifications of more than $2 \mathrm{~mm}$ or one ossification or more than $3 \mathrm{~mm}$;

Grade III: two or more ossifications of more than $3 \mathrm{~mm}$.

Probands with grades 0 or I were considered to be 'shoulder hyperostosis absent' (controls), those with grades II or III as 'shoulder hyperostosis present'. Probands without shoulder and without thoracospinal hyperostosis were considered as 'shoulder DISH absent' (controls), those with shoulder hyperostosis and with thoracospinal hyperostosis were considered as 'shoulder DISH present'. In addition the presence of amorphous soft tissue calcification was noted.

The intra- and interobserver reliability of grading of thoracospinal and shoulder radiographs was assessed by calculating $P_{\mathrm{o}}$ (observed proportion of agreement) and kappa (statistic for agreement beyond chance expectation) [14]:

$$
\text { Kappa } \mathrm{K}=\frac{P_{\mathrm{o}}-P_{\mathrm{e}}}{1-P_{\mathrm{e}}}
$$

where $P_{\mathrm{e}}=$ expected proportion of agreement and $P_{\mathrm{o}}$ $=$ observed proportion of agreement.

Statistical calculations were based on the chisquared test for dichotomous variables and the Student's $t$-test for continuous variables. The level of statistical significance was set at $P=0.05$ with twosided analysis.

The study was approved by the Ethical Committee of the University of Berne.

\section{RESULTS \\ Probands studied, demographic data}

Of the 284 probands, 99 (34 with/65 without shoul- der hyperostosis) had a complete radiological examination of the thoracic spine and both shoulders. The acceptance of all X-rays was independent of thoracospinal hyperostosis $(37 \%$ in thoracospinal hyperostosis versus $34 \%$ in controls, $\chi^{2}=0.28, \mathrm{NS}, n=284$ ) or extraskeletal pain $(36 \%$ in probands with extraskeletal pain versus $34 \%$ without, $\chi^{2}=0.07, \mathrm{NS}$ ). In addition, there was no relevant difference in the frequency of shoulder X-rays in probands with or without shoulder pain $\left(40 \%\right.$ versus $\left.32 \%, \chi^{2}=3.67, \mathrm{NS}\right)$. We conclude that these results make a selection bias unlikely. The 99 probands were used for the evaluation of the association of the radiological findings of shoulder and thoracospinal hyperostosis. However, for further evaluation, 25 probands $(9$ with/16 without shoulder hyperostosis) had to be excluded because of a history of major shoulder trauma $(n=5$ with $/ 4$ without shoulder hyperostosis, respectively), osteoarthritis ( $n$ $=1 / 6$, respectively), distinct osteopenia $(n=2 / 2$, respectively), chondrocalcinosis $(n=1 / 1$, respectively), erosive arthritis ( $n=0 / 2$, respectively) and incidentally detected bone metastasis $(n=0 / 1$, respectively). The remaining 74 probands ( 25 with/49 without shoulder hyperostosis) were used for the evaluation of the association of a history of shoulder pain and shoulder hyperostosis, irrespective of thoracospinal hyperostosis. Demographic data are shown in Table I. For further evaluation 27 probands (12 with shoulder hyperostosis but without thoracospinal hyperostosis/15 without shoulder hyperostosis but with thoracospinal hyperostosis) were excluded (Table II). The remaining 47 probands ( 13 with $/ 34$ without shoulder DISH) were used for the evaluation of the association of a history of shoulder pain and shoulder DISH. Demographic data were similar to Table I.

The intra- and interobserver reliability was excellent for thoracospinal assessment $\left(P_{\mathrm{o}} 0.90-0.95\right.$, kappa $0.80-0.90, n=55-60$ ). There were no major differences between three rheumatologists (PS, NJG, HF) and a radiologist (WAF). In comparing lateral chest films with lateral spinal films there was satisfactory agreement $\left(P_{0}=0.85\right.$, kappa $\left.=0.70, n=87\right)$. Overall, lateral chest films showed slightly less often hyperostotic features compared with lateral spinal films. The intra- and interobserver reliability was only fair for the shoulder assessment $\left(P_{o}=0.75-0.78\right.$, kappa 0.50 $0.56, n=24-105$ ).

TABLE I

Synopsis of Clinical and Radiological Characteristics

\begin{tabular}{|c|c|c|c|}
\hline & \multicolumn{3}{|c|}{$\begin{array}{c}\text { Shoulder hyperostosis (with or without thoracospinal } \\
\text { hyperostosis) }\end{array}$} \\
\hline & $\begin{array}{c}\text { present } \\
(n=25)\end{array}$ & $\begin{array}{c}\text { absent } \\
(n=49)\end{array}$ & \\
\hline Age years (mean $\pm \mathrm{SD})$ & $68 \pm 8$ & $65 \pm 9$ & NS \\
\hline Males & $21(84 \%)$ & $36(73 \%)$ & NS \\
\hline History of heavy work & $18(72 \%)$ & $25(51 \%)$ & NS \\
\hline Extraskeletal pain & $7(28 \%)$ & $26(53 \%)$ & $P<0.05$ \\
\hline Amorphous soft tissue calcification & $2(8 \%)$ & $10(20 \%)$ & NS \\
\hline
\end{tabular}

74 probands with or without shoulder hyperostosis, irrespective of thoracospinal hyperostosis. 


\begin{tabular}{lccc}
\hline \multicolumn{3}{c}{ TABLE II } \\
\hline & \multicolumn{3}{c}{ Thoracospinal hyperostosis DISH } \\
\cline { 2 - 4 } & present & absent & total \\
\hline & 13 & 12 & 25 \\
$\begin{array}{l}\text { Shoulder hyperostosis } \\
\text { present } \\
\text { absent }\end{array}$ & 15 & 34 & 49 \\
\cline { 2 - 4 } Total & 28 & 46 & 74 \\
\hline
\end{tabular}

In probands with thoracospinal hyperostosis the prevalence of shoulder hyperostosis was doubled compared to controls $\left(49 \%\right.$ versus $25 \%, \chi^{2}=5.90$, $P<0.025, n=99$ ) (Table III), illustrating the multifocal character of DISH. In addition, all probands with shoulder hyperostosis showed bilateral hyperostotic features.

Analysing 257 probands (96 with, 161 without thoracospinal hyperostosis) after exclusion of 27 probands with major shoulder trauma (10 with, 17 without thoracospinal hyperostosis), the prevalence of a history of shoulder pain any time in the past was the same in probands with thoracospinal hyperostosis and controls ( $28 \%$ versus $\left.28 \%, \chi^{2}=0.001, \mathrm{NS}\right)$.

Analysing 74 probands ( 25 with, 49 without shoulder hyperostosis), the prevalence of shoulder pain any time in the past in probands with shoulder hyperostosis was about doubled compared to controls ( $40 \%$ versus $18 \%, \chi^{2}=4.06, P<0.05$ ) (Table IV). Differentiating between a history of shoulder pain during the last 6 months and previously the results were $16 \%$ versus $8 \%, \chi^{2}=1.05$, NS and $36 \%$ versus $14 \%, \chi^{2}=4.61$, $P<0.05$, respectively.

The groups did not differ greatly in demographic data such as age, sex or history of heavy work, nor in the frequency of amorphous soft tissue calcification unattached to bone (Table I). However, actual referral to hospital because of extraskeletal pain due to coronary heart disease $(n=23)$, abdominal disorder $(n=5)$, neuropathy $(n=4)$ or peripheral vascular disease $(n=$ 1) was more prevalent in controls ( $53 \%$ versus $28 \%, \chi^{2}$ $=4.21, P<0.05)($ Table I $)$.

Analysing 47 probands (13 with, 34 without shoulder DISH), the prevalence of shoulder pain at any time in the past was almost four times higher compared to controls $\left(46 \%\right.$ versus $\left.12 \%, \chi^{2}=6.64, P<0.01\right)$ (Table V).
TABLE III

Shoulder Hyperostosis in Thoracospinal Hyperostosis

\begin{tabular}{|c|c|c|c|}
\hline & \multicolumn{3}{|c|}{ Thoracospinal hyperostosis DISH } \\
\hline & present & absent & total \\
\hline $\begin{array}{l}\text { Shoulder hyperostosis } \\
\text { present } \\
\text { absent }\end{array}$ & $\begin{array}{ll}19 & (49 \%) \\
20 & (51 \%)\end{array}$ & $\begin{array}{ll}15 & (25 \%) \\
45 & (75 \%)\end{array}$ & $\begin{array}{ll}34 & (34 \%) \\
65 & (66 \%)\end{array}$ \\
\hline Total & $39(100 \%)$ & $60(100 \%)$ & $99(100 \%)$ \\
\hline
\end{tabular}

$\chi^{2}=5.90, P<0.025$

The pain prevalence during the last 6 months and prior to the last 6 months was $29 \%$ versus $3 \%, \chi^{2}=4.90$, $P<0.05$ and $38 \%$ versus $9 \%, \chi^{2}=5.85, P<0.025$, respectively.

The groups did not differ greatly in demographic data such as age, sex or history of heavy work nor in the frequency of amorphous soft tissue calcification unattached to bone. Actual referral to hospital because of extraskeletal pain due to coronary heart disease $(n=$ $16)$, abdominal disorder $(n=3)$, neuropathy $(n=1)$ or peripheral vascular disease $(n=1)$ was slightly more prevalent in controls $\left(53 \%\right.$ versus $29 \%, \chi^{2}=3.39$, $P<0.10)$.

\section{DISCUSSION}

This is the first controlled study concerning shoulder hyperostosis. Although transient or chronic shoulder pain is a common complaint and shoulder hyperostosis is a frequent radiological condition in the elderly, predominantly in males $[3,10,12]$, little is known about the association between the radiological findings and subjective complaints.

Our results revealed a doubled prevalence of shoulder hyperostosis in probands with thoracospinal hyperostosis, compared to probands without thoracospinal hyperostosis. This illustrates the multifocal character of the condition [3-5]. Half of the probands with thoracospinal hyperostosis showed shoulder hyperostosis, pointing to the frequent extraspinal manifestations of DISH. In contrast, only one-quarter of the probands without thoracospinal hyperostosis showed shoulder hyperostosis. It has been shown that extraspinal manifestations can precede the spinal findings [6]. In addition, ligamentous or capsular ossification of the

TABLE IV

Prevalence of a History of Shoulder Pain in the Past in Shoulder Hyperostosis Irrespective of Thoracospinal Hyperostosis COMPARED TO CONTROLS

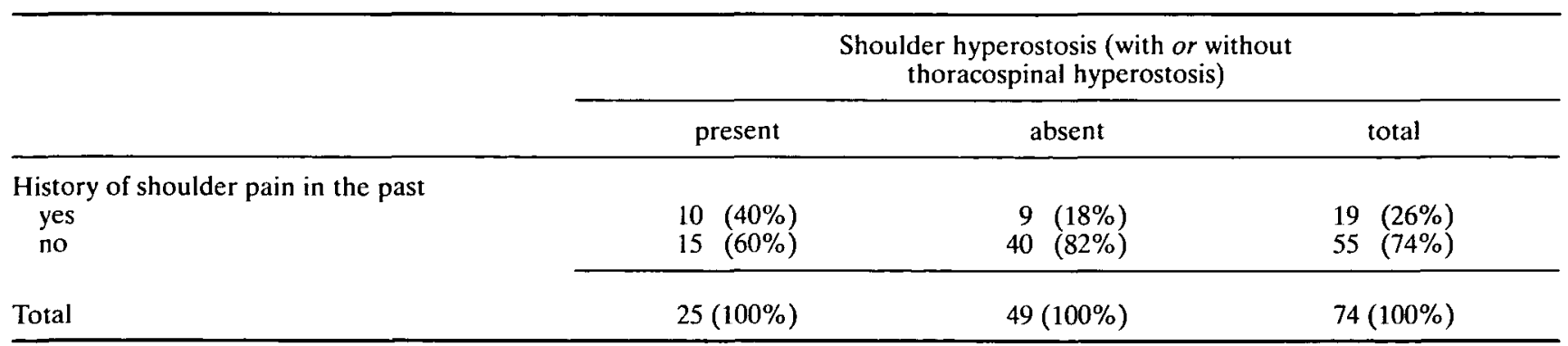

$\chi^{2}=4.06, P<0.05$. 
TABLE V

Prevalence of a History of Shoulder Pain in the Past in Shoulder Dish Compared to Control.s

\begin{tabular}{|c|c|c|c|}
\hline & \multicolumn{3}{|c|}{$\begin{array}{l}\text { Shoulder DISH } \\
\text { (shoulder and thoracospinal hyperostosis) }\end{array}$} \\
\hline & present & absent & total \\
\hline \multicolumn{4}{|c|}{ History of shoulder pain in the past } \\
\hline yes & $6(46 \%)$ & $4(12 \%)$ & $10(21 \%)$ \\
\hline no & $7(54 \%)$ & $30(88 \%)$ & $37(79 \%)$ \\
\hline Total & $13(100 \%)$ & $34(100 \%)$ & $47(100 \%)$ \\
\hline
\end{tabular}

$\chi^{2}=6.64, P<0.01$.

shoulder is not specific for DISH, but occurs in diseases such as ankylosing spondylitis [15, 16], acromegaly, and calcium pyrophosphate deposition disease [3]. The radiological criteria used for shoulder hyperostosis grading revealed a modest intra- and interobserver reliability. This may be due in part to the complexity of the shoulder joint. In addition, the differentiation between hyperostotic spurs and osteoarthrotic osteophytes of the glenoid or acromioclavicular joint can be difficult. This was felt to be a practical problem in only five probands ( 1 with/4 without thoracospinal hyperostosis). The differentiation between hyperostotic spurs and soft tissue calcification can be difficult. In this study, it was not of practical importance. The prevalence of amorphous soft tissue calcification unattached to bone turned out to be comparable in the groups with and without shoulder hyperostosis.

The radiological findings of DISH at the shoulder joint are frequent but their clinical relevance has not been established. Uncontrolled studies described shoulder pain in $5-29 \%$ of the selected probands $[3,4$, $7,13]$. Our controlled study used probands hospitalized for medical and surgical disorders not related to diseases of the locomotor system.

Thoracospinal hyperostosis did not seem to predispose to spinal pain at any level $[17,18]$. In contrast, the results of this study support the hypothesis that shoulder hyperostosis may predispose to shoulder pain. In probands with shoulder hyperostosis with or without thoracospinal hyperostosis, the prevalence of shoulder pain in the past was about double compared to controls. In probands with shoulder and thoracospinal hyperostosis (shoulder DISH) the prevalence was almost four times higher. The relative risk for developing shoulder pain was 2.18 and 3.92 respectively. The prevalence of shoulder pain in the past $(40-46 \%)$ was higher compared to the results of other published series $(5-29 \%)[3,4,7,13]$. Referral to hospital due to extraskeletal pain was more prevalent in controls. One cannot exclude the possibility that controls tended to understate their past shoulder pain because of present symptoms. This is a potential problem in every retrospective study relying on data obtained by questionnaire.

From these results we conclude that shoulder hyperostosis may be a condition of clínical relevance. Taking into account the high prevalence of DISH in individuals over the age of 50 , if seems likely that 'periarthritic shoulder pain', either recurrent or chronic, may be related in part to hyperostosis of the shoulder skeleton.

\section{ACKNOWLEDGEMENTS}

We thank Dr Esther Hächler for interviewing probands, $\mathrm{Dr}$ Ch. Minder for statistical consulting. We thank all colleagues of the Departments of Internal Medicine (Prof. P. W. Straub, Prof. H. Studer, Prof. T. Hess) and Cardiovascular Surgery (Prof. U. Althaus), Inselspital, Berne, for making available their patients to our study. Finally we thank Mrs E. Gerny and Mrs D. Eicher for secretarial help.

\section{REFERENCES}

1. Forestier J, Rotes-Querol J. Senile ankylosing hyperostosis of the spine. Ann Rheum Dis 1950; 9: $321-30$.

2. Forestier J, Lagier R. Ankylosing hyperostosis of the spine. Clin Orthop Rel Res 1971; 74: 65-83.

3. Resnick D, Shapiro RF, Wiesner KB, Niwayama G, Utsinger PD, Shaul SR. Diffuse idiopathic skeletal hyperostosis (DISH) [ankylosing hyperostosis of Forestier and Rotes-Ouerol]. Semin Arthritis Rheum 1978; 7: 153-87.

4. Utsinger PD. Diffuse idiopathic skeletal hyperostosis. Clin Rheum Dis 1985; 11: 325-51.

5. Arlet J, Mazières B. La maladie hyperostosique. Rev Med Interne 1985; 6: 553-64.

6. Resnick D, Niwayama G. Radiographic and pathologic features of spinal involvement in diffuse idiopathic skeletal hyperostosis. Radiology 1976; 119: $559-68$.

7. Harris J, Carter AR, Glick EN, Storey GO. Ankylosing hyperostosis. Clinical and radiological features. Ann Rheum Dis 1974; 33: 210-15.

8. Resnick D, Staul SR, Robins JM. Diffuse idiopathic skeletal hyperostosis (DISH): Forestier's disease with extraspinal manifestations. Radiology 1975; 115: 513-24.

9. Utsinger PD, Resnick D, Shapiro R. Diffuse skeletal abnormalities in Forestier's disease. Arch Intern Med 1976; 136: 763-8.

10. Robotti GC, Schneekloth G. Extravertebrale Manifestationen der ankylosierenden Hyperostose (M. Forestier). Radiologie 1982; 22: 408-11.

11. Littlejohn GO, Urowitz MB. Peripheral enthesopathy in diffuse idiopathic skeletal hyperostosis 
(DISH): a radiological study. $J$ Rheumatol 1982; 9 : 568-72.

12. Fournié B, Railhac JJ, Ayrolles Ch, Fournié A L'épaule hyperostosique. Rev Rhum 1984; 51: 389-92.

13. Garf AE, Khater R. Diffuse idiopathic skeletal hyperostosis (DISH), a clinicoradiological study of the disease pattern in middle eastern population. $J$ Rheumatol 1984; 11: 804-7.

14. Kelsey JL, Thompson WD, Evans AS. Methods in observational epidemiology. Monographs in epidemiology and biostatistics. Vol 10. Oxford: Oxford University Press, 1986: 288-93.
15. Paolaggi JB, Coutet MC, Strutz Ph, Siaud JR, Le Parc JM, Auquier L. Les enthesopathies des spondylarthopathies inflammatoires. Rev Rhum 1984; 51: 457-62.

16. Fournié B, Railhac JJ, Monod P, Valverde C, Barbe JJ, Fournié A. L'épaule enthesopathique. Rev Rhum 1987; 54: 447-51.

17. Schlapbach P, Beyeler Ch, Gerber NJ, et al. Diffuse idiopathic skeletal hyperostosis (DISH): a cause of back pain? A controlled study. $B r J$ Rheumatol 1989; 28: 299-303.

18. Hutton C. DISH . . . a state not a disease? (Editorial) Br J Rheumatol 1989; 28: 277-8.

\section{NOTICES}

\section{XIIth EUROPEAN CONGRESS OF RHEUMATOLOGY, BUDAPEST}

Dates: 30 June-6 July 1991

Venue: Budapest, Hungary

Further information: R'91 Congress Secretariat, Budapest 23, PO Box 62, H-1277, Hungary

Deadline for abstracts and registration: 30 December 1990

\section{INTERNATIONAL CONFERENCE AND INSTRUCTIONAL COURSE ON ORTHOTICS}

Dates: 16-20 September 1991

Venue: Dundee, Scotland

Information: Dundee ' 91 Secretariat, c/o Dundee Limb Fitting Centre, 133 Queen Street, Broughty Ferry, Dundee, Scotland DD5 $1 \mathrm{AG}$ 